\title{
Modelling irrigation strategies to minimize deep drainage for two different climatic regions of Canada
}

\author{
G. Parkin \& S. Wang \\ University of Guelph, Guelph, Ontario, Canada
}

\begin{abstract}
Irrigation is a vital part of agriculture in certain regions of Canada including the interior of British Columbia. In this study we examined the use of a soil water budget model for efficient irrigation management in two contrasting climatic regions of British Columbia: Abbotsford (AD) and Osoyoos (OS). The average annual precipitation at $\mathrm{AD}$ and $\mathrm{OS}$ are 1573 and $318 \mathrm{~mm}$, respectively. The soil types (AD - silt loam and $\mathrm{OS}$ - sand) and major crops (AD - raspberry and OS apple) are also quite different between the two regions. We used the Simultaneous Heat and Water (SHAW) model to estimate the amount of deep drainage and soil water content under different irrigation management strategies. The SHAW model integrates detailed physics of vegetative cover, snow, residue and soil into one simultaneous solution. The model was run on a daily basis for 28 and 32 years for $\mathrm{AD}$ and OS regions, respectively. Different combinations of crop and irrigation conditions were run for each region. Based on this study, the "best" irrigation management strategy involves triggering every irrigation event when the soil water content (estimated by SHAW) in crop's rooting zone reaches a prescribed amount below field capacity. At that time, $40 \mathrm{~mm}$ of irrigation is added as rainfall. Other strategies involved adding more irrigation and a constant weekly irrigation regardless of rainfall and soil water content. In conclusion, while most of deep drainage in the dormant seasons (no irrigation) cannot be controlled, it can be well controlled to a minimum level in the growing seasons by "best" irrigation management practice.
\end{abstract}

Keywords: irrigation modelling, minimize drainage, Canadian conditions. 


\section{Introduction}

Irrigation of field crops is required in certain regions of Canada to maintain consistent crop yield and quality. In the province of British Columbia (BC), approximately 190,000 hectares were under irrigation in 1995 [1]. Forage crops were grown on about $85 \%$ of the irrigated land with tree fruits, vegetables, and berries together comprising about $11 \%$. The focus of this study is on a tree fruit (apple) and a berry (raspberry) as they are high-value, intensively grown crops.

Water-use efficiency (WUE) is an important consideration in terms of designing an irrigation management system. In fact, improving agricultural WUE is a key element in coping with future water demands [2]. Excessive irrigation has been cited as a possible contributing factor to elevated levels of nitrate in some domestic wells in the two regions of $\mathrm{BC}$ selected for this study (Abbotsford, AD and Osoyoos, OS) [3]. The goal of this study was to investigate WUE for these two regions of $\mathrm{BC}$ using a model to estimate the relative amount of drainage under various irrigation management strategies. The "best" irrigation scheduling strategy is assumed to minimize the amount of drainage yet still provide sufficient available soil water for plant growth.

The Simultaneous Heat and Water (SHAW) model is a one-dimensional physical-process model, which simulates detailed heat and water movement through the vegetative cover, snow, residue cover and soil [4]. The model enables detailed simulation of water and energy flux at the atmospheric-soil interface and within the soil profile, and includes the effects of vegetation, snow, crop residue cover and soil freezing. It has been used for many applications including estimating soil water budgets and temperatures, snowmelt dynamics, components of net all wave radiation, and timing manure application [5-8]. To our knowledge, it has never been used to assess WUE of different irrigation management strategies. The SHAW model was chosen for this study as it is physically-based and includes the effects of freezing and thawing processes on water movement, which is an important selection criterion for non-growing season conditions in most of Canada.

The main objective of this study was to use the SHAW model to estimate the amount of drainage under efficient and less-efficient irrigation management systems for two vastly different climatic regions of British Columbia, Canada.

\subsection{Background information}

The location and climate normals for the two study sites (AD: $49^{\circ} 02^{\prime}$ N, $122^{\circ} 22^{\prime}$ W, 59 m a.s.1.; OS: $49^{\circ} 02^{\prime} \mathrm{N}, 119^{\circ} 26^{\prime} \mathrm{W}, 297 \mathrm{~m}$ a.s.1.) are given in Table 1 . As discussed previously these two sites were chosen because of their vastly different climatic regimes yet irrigation of intensively-grown crops is a common practice in both regions. The average annual precipitation at $\mathrm{AD}$ is nearly five times that at OS; however, due to relatively low amount of summer rainfall, irrigation is still generally required at AD. The average annual temperature at the two sites is essentially the same even though summer and winter season temperatures are normally higher and lower, respectively at OS. These differences in 
precipitation, and to a lesser extent temperature, should lead to significant differences in the amounts of drainage even without irrigation for the two regions; the SHAW model results will confirm\deny this hypothesis.

Table 1: $\quad$ A comparison of some monthly climate normals for 1971-2000 for the two study sites.

\begin{tabular}{|l|c|c|c|c|}
\hline \multirow{2}{*}{ Month } & \multicolumn{2}{|c|}{ Precipitation $(\mathrm{mm})$} & \multicolumn{2}{c|}{$\begin{array}{c}\text { Average Daily Temperature } \\
\left({ }^{\circ} \mathrm{C}\right)\end{array}$} \\
\cline { 2 - 5 } & Abbotsford & Osoyoos & Abbotsford & Osoyoos \\
\hline January & 198 & 28 & 2.6 & -2.1 \\
\hline February & 160 & 26 & 4.7 & 1.1 \\
\hline March & 146 & 23 & 6.8 & 6 \\
\hline April & 120 & 24 & 9.5 & 10.8 \\
\hline May & 99 & 37 & 12.5 & 15.1 \\
\hline June & 79 & 36 & 15.1 & 18.7 \\
\hline July & 50 & 24 & 17.5 & 21.7 \\
\hline August & 49 & 21 & 17.7 & 21.3 \\
\hline September & 76 & 16 & 15 & 16.2 \\
\hline October & 145 & 17 & 10.2 & 9.8 \\
\hline November & 241 & 32 & 5.7 & 3.5 \\
\hline December & 209 & 34 & 2.8 & -1.2 \\
\hline Average Annual & 1573 & 318 & 10.0 & 10.1 \\
\hline
\end{tabular}

\section{Methodology}

Estimates of deep drainage under different irrigation management strategies and a control were determined using the SHAW model. The control model runs were completed under local soil and climatic conditions with no crop planted and zero irrigation applied. The first irrigation management strategy (I40) was designed to minimize the amount of drainage yet maintain enough available soil water to sustain the crop grown in each region. For both regions, $40 \mathrm{~mm}$ (roughly equal to the amount of available water in the top $100 \mathrm{~cm}$ of each soil profile assuming a reasonable deficit coefficient) of irrigation was applied as additional daily rainfall when the soil water content decreased to a prescribed level as estimated by the SHAW model under a raspberry crop at AD and apple trees at OS. Soil volumetric water contents of 0.15 and 0.10 triggered irrigation at $\mathrm{AD}$ and $\mathrm{OS}$, respectively. Irrigation increased the soil water content to about 0.19 and 0.15 in the respective regions, which are slightly below field capacity of the two local soils providing good growing conditions while presumably minimizing drainage losses. As a test of the efficiency of I40 a second strategy (I60) was tested for the AD region only by adding $60 \mathrm{~mm}$ to the rainfall input file of SHAW instead of $40 \mathrm{~mm}$ when irrigation was required according to the model estimate of soil water content as discussed previously. A third irrigation strategy was tested only in the semi-arid OS region; this strategy (IW40) applied $40 \mathrm{~mm}$ of irrigation to the apple trees each week regardless of the soil water content.

The main inputs to the SHAW model include: initial soil temperature and water content profiles, daily weather conditions, and parameters describing the 
vegetative cover, snow, plant residue and soil. General site information includes slope, aspect, latitude, and surface roughness parameters. Plant residue or litter properties include residue loading, thickness of the residue layer, percent cover and albedo. Input soil parameters are dry bulk density, saturated hydraulic conductivity, coefficients for the matric potential-water content relation, and the albedo-water content relation. Some of the physical properties of the soils selected to represent the two study regions are given in Table 2.

Table 2: $\quad$ Select soil physical properties used in the SHAW model to represent local soils at the two study regions.

\begin{tabular}{|c|c|c|c|c|c|c|c|c|c|c|c|c|c|c|c|}
\hline $\begin{array}{c}\text { Depth } \\
(\mathrm{cm})\end{array}$ & \multicolumn{2}{|c|}{ Texture } & \multicolumn{2}{c|}{$\%$ Clay } & \multicolumn{2}{c|}{$\%$ Silt } & \multicolumn{2}{c|}{$\%$ Sand } & \multicolumn{2}{c|}{$\%$ OM } & \multicolumn{3}{|c|}{ WP } & \multicolumn{2}{|c|}{ FC } \\
\cline { 2 - 16 } & AD & OS & AD & OS & AD & OS & AD & OS & AD & OS & AD & OS & AD & OS \\
\hline $0-20$ & SiL & Lsa & 15 & 10 & 65 & 6 & 20 & 84 & 1.0 & 1.0 & 0.11 & 0.09 & 0.30 & 0.18 \\
\hline $20-50$ & SiL & Sa & 15 & 10 & 65 & 6 & 20 & 84 & 0.5 & 0.5 & 0.11 & 0.09 & 0.28 & 0.16 \\
\hline $50-\mathrm{B}$ & Sa & Lsa & 6 & 6 & 4 & 4 & 90 & 90 & 0 & 0 & 0.06 & 0.06 & 0.15 & 0.12 \\
\hline
\end{tabular}

\begin{tabular}{|c|c|c|c|c|c|c|c|c|c|c|c|c|}
\hline \multirow{2}{*}{$\begin{array}{c}\text { Depth } \\
(\mathrm{cm})\end{array}$} & \multicolumn{2}{|c|}{ ASWC } & \multicolumn{2}{|c|}{ Porosity } & \multicolumn{2}{c|}{ BD } & \multicolumn{2}{c|}{ AE $(\mathrm{cm})$} & \multicolumn{2}{|c|}{ PSDI } & \multicolumn{2}{c|}{ Ksat } \\
\cline { 2 - 14 } & AD & OS & AD & OS & AD & OS & AD & OS & AD & OS & AD & OS \\
\hline $0-20$ & 19 & 8.8 & 0.53 & 0.41 & 1.21 & 1.50 & -47 & -18 & 3.60 & 4.08 & 16 & 3.9 \\
\hline $20-50$ & 17 & 7.6 & 0.46 & 0.39 & 1.37 & 1.56 & -48 & -14 & 3.86 & 4.11 & 1.6 & 2.6 \\
\hline $50-\mathrm{B}$ & 9.4 & 5.9 & 0.41 & 0.40 & 1.52 & 1.52 & -18 & -18 & 2.97 & 2.97 & 10.9 & 10.9 \\
\hline
\end{tabular}

$\mathrm{AD}=$ Abbotsford; $\mathrm{OS}=$ Osoyoos; $\mathrm{Lsa}=$ loamy sand; $\mathrm{Sa}=$ sand; $\mathrm{SiL}=$ silt loam;

$\mathrm{OM}=$ organic matter; $\mathrm{WP}=$ wilting point $\mathrm{FC}=$ field capacity; $\mathrm{ASWC}=$ available soil water content $\left(\mathrm{cmm}^{-1}\right) ; \mathrm{BD}=$ bulk density $\left(\mathrm{gcm}^{-3}\right) ; \mathrm{AE}=$ air-entry pressure head $(\mathrm{cm}) ;$ PSDI $=$ pore-size distribution index; Ksat $=$ saturated hydraulic conductivity $\left(\mathrm{cmhr}^{-1}\right) . \mathrm{B}=150 \mathrm{~cm}$ for Abbotsford and $200 \mathrm{~cm}$ for Osoyoos.

The SHAW model does not have an independent crop-growth module; it requires crop growth information as part of the input data set. The relevant cropgrowth information for raspberry and apple crops grown at $\mathrm{AD}$ and $\mathrm{OS}$, respectively as used in the SHAW model for this study are listed in Table 3. The daily climate data including maximum and minimum air temperatures, dew-point temperature, total wind run, precipitation, and sunshine hours (converted to solar radiation using the method given in [9]) were obtained from Environment Canada for the two regions. Climate data were available from 1971-1998 for $\mathrm{AD}$ and 1968-1999 for OS.

\section{Results and discussion}

\subsection{Abbotsford (AD) Region}

Table 4 gives average annual estimates of the water balance from SHAW for the $\mathrm{AD}$ region under different irrigation management strategies. Of the $351 \mathrm{~mm}$ of irrigation that is applied under the I40 system, it appears that only about $15 \%$ was lost as drainage increased by an average of $55 \mathrm{~mm}$ over the Control system. 
Table 3: Crop-growth information used in this study as input for SHAW model for Osoyoos (OS) and Abbotsford (AD).

OS.

\begin{tabular}{|c|c|c|c|c|}
\hline Stage of Development & Time Period & $\begin{array}{c}\text { Dry biomass } \\
\left(\mathrm{kg} / \mathrm{m}^{2}\right)\end{array}$ & LAI & $\begin{array}{c}\text { Rooting Depth } \\
(\mathrm{m})\end{array}$ \\
\hline Initial & Apr 15 - May 5 & 1.0 & $0-1.0$ & 1.0 \\
\hline Crop development & May 6 - Jun 24 & $1.0-1.5$ & $1.0-2.0$ & 1.0 \\
\hline Mid-season & Jun 25 - Sep 22 & 2.0 & 2.0 & 1.0 \\
\hline Late-season 1 & Sep 22 - Oct 12 & $2.0-1.5$ & $2.0-1.5$ & 1.0 \\
\hline Late-season 2 & Oct 13 - Nov 15 & $1.5-1.0$ & $1.5-0$ & 1.0 \\
\hline
\end{tabular}

$\mathrm{AD}$.

\begin{tabular}{|c|c|c|c|c|c|}
\hline Day of year & Height $(\mathrm{m})$ & Leaf width $(\mathrm{cm})$ & Dry Biomass $\left(\mathrm{kg} / \mathrm{m}^{2}\right)$ & LAI & Rooting depth $(\mathrm{m})$ \\
\hline 91 & 1 & 0 & 1.3 & 0 & 1.0 \\
\hline 120 & 1.5 & 6 & 1.9 & 3 & 1.0 \\
\hline 165 & 2 & 6 & 2.7 & 4 & 1.0 \\
\hline 193 & 2 & 6 & 3.7 & 4 & 1.0 \\
\hline 212 & 2 & 6 & 3.4 & 4 & 1.0 \\
\hline 227 & 2 & 6 & 3.2 & 4 & 1.0 \\
\hline 262 & 2 & 6 & 2.6 & 2.5 & 1.0 \\
\hline 273 & 2 & 6 & 2.4 & 2 & 1.0 \\
\hline 319 & 1.5 & 0 & 1.9 & 0 & 1.0 \\
\hline
\end{tabular}

$\mathrm{LAI}=$ leaf-area index.

On the other hand, on average, all of the increase in irrigation applied under system I60 was lost to drainage as estimated by SHAW. The average annual amount of evapotranspiration remained essentially the same for I40 and I60 suggesting that the additional irrigation applied under I60 did not increase plant growth.

The year-to-year variability is greatest for runoff (coefficient of variation $>$ $100 \%$ ); in fact the annual estimate of runoff ranges from 0 to $209 \mathrm{~mm}$. The coefficient of variation for drainage is about $23 \%$ only slightly higher than precipitation at $16 \%$; however, there is enough year-to-year variability to warrant caution when using long-term estimates of average drainage to guide water resource policy development for example (Figure 1). For every modelled year the SHAW-estimated drainage for I60 exceeds I40. As well, data shown in Figure 1 suggests that there is a reasonably strong correlation between annual precipitation and drainage. Since drainage is difficult to measure in the field it may be useful to be able to estimate it based on the annual amount of precipitation. Figure 2 shows that over $80 \%$ of the variability in annual drainage estimated by SHAW is explained by variability in annual precipitation, which suggests this simple approach to estimating annual drainage may be viable for the AD region. 
Table 4: $\quad$ Summary of average (standard deviation in brackets) annual water balance components (all in $\mathrm{mm}$ ) estimated by SHAW model for three irrigation systems at Abbotsford site.

\begin{tabular}{|c|c|c|c|c|c|}
\hline $\begin{array}{c}\text { Irrigation } \\
\text { System }\end{array}$ & $\mathrm{P}$ & $\mathrm{I}$ & $\mathrm{E}+\mathrm{T}$ & Drainage & Runoff \\
\hline Control & $\begin{array}{c}1586 \\
(253)\end{array}$ & 0 & $690(62)$ & $844(222)$ & $52(60)$ \\
\hline I40 & $\begin{array}{r}1586 \\
(253)\end{array}$ & $\begin{array}{c}351 \\
(97)\end{array}$ & $985(48)$ & $899(217)$ & $54(68)$ \\
\hline I60 & $\begin{array}{c}1586 \\
(253)\end{array}$ & $\begin{array}{c}527 \\
(146)\end{array}$ & $984(48)$ & $1076(210)$ & $54(67)$ \\
\hline
\end{tabular}

$\mathrm{P}=$ precipitation; $\mathrm{I}=$ irrigation $; \mathrm{E}+\mathrm{T}=$ Evaporation + Transpiration.

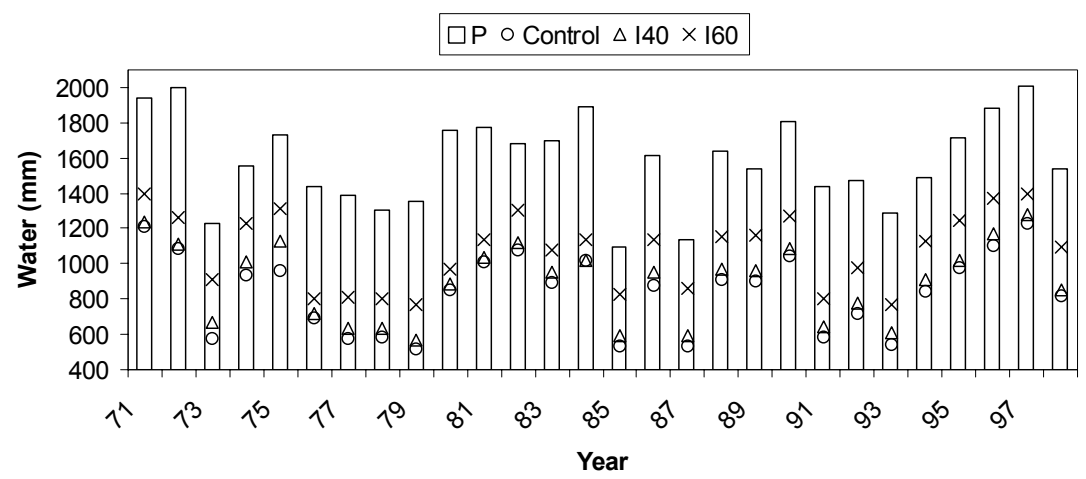

Figure 1: A comparison of annual precipitation and SHAW-estimated drainage for control, I40 and I60 irrigation systems in Abbotsford region. Note $\mathrm{P}=$ precipitation.

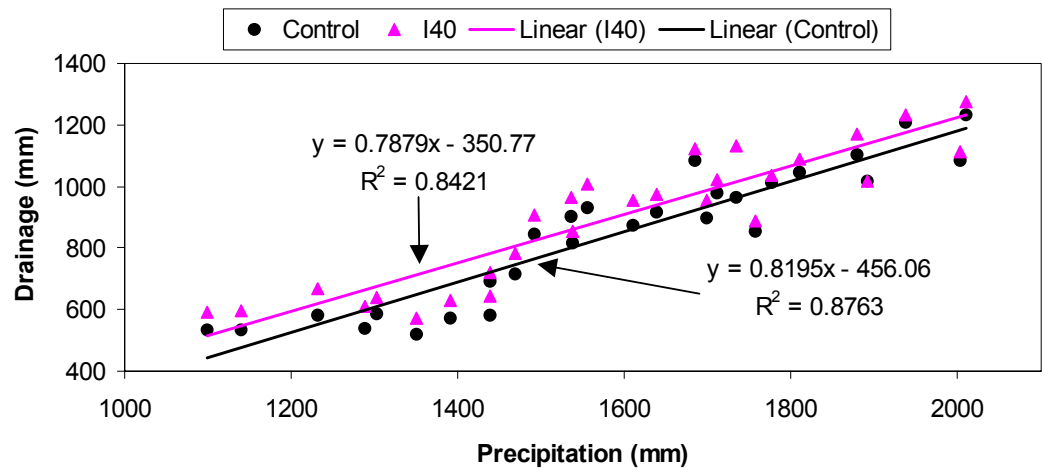

Figure 2: Relationship between annual drainage and precipitation for control and $\mathrm{I} 40$ irrigation system in Abbotsford region.

The SHAW model estimates that most deep drainage occurs in the winter and fall seasons; on average, the winter and fall account for $68 \%$ and $20 \%$ of total 
annual deep drainage, respectively (data not shown). Runoff usually occurs in the late winterlearly spring seasons when the snow pack melts and a thin soil layer near surface is still frozen and thus the melted snow cannot infiltrate.

\subsection{Osoyoos (OS) Region}

The climate at OS is much drier than at $\mathrm{AD}$; therefore, it is anticipated that the average annual drainage would be much less at OS - the SHAW model estimates bear this out (compare Tables 4 and 5). The SHAW-estimated amount of evapotranspiration at OS increased nearly 4-fold under the I40 system, which applied on average over $750 \mathrm{~mm}$ of irrigation per year, yet the estimated amount of drainage actually decreased in comparison to Control. On the other hand, about $84 \%$ of the additional amount of irrigation applied under IW40 (319 mm) was lost to drainage as SHAW-estimated average annual evapotranspiration only increased by $50 \mathrm{~mm}$.

Table 5: $\quad$ Summary of average (standard deviation in brackets) annual water balance components (all in $\mathrm{mm}$ ) estimated by SHAW model for three irrigation systems at Osoyoos.

\begin{tabular}{|c|c|c|c|c|c|}
\hline $\begin{array}{c}\text { Irrigation } \\
\text { System }\end{array}$ & $\mathrm{P}$ & $\mathrm{I}$ & $\mathrm{E}+\mathrm{T}$ & Drainage & Runoff \\
\hline Control & 318 & 0 & 290 & 25 & 2 \\
& $(79)$ & & $(57)$ & $(26)$ & $(7)$ \\
\hline I40 & 318 & 761 & 1062 & 12 & 4 \\
& $(79)$ & $(107)$ & $(78)$ & $(16)$ & $(11)$ \\
\hline IW40 & 318 & 1080 & 1112 & 279 & 5 \\
& $(79)$ & $(0)$ & $(73)$ & $(109)$ & $(12)$ \\
\hline
\end{tabular}

$\mathrm{P}=$ precipitation; $\mathrm{I}=$ irrigation $; \mathrm{E}+\mathrm{T}=$ Evaporation + Transpiration.

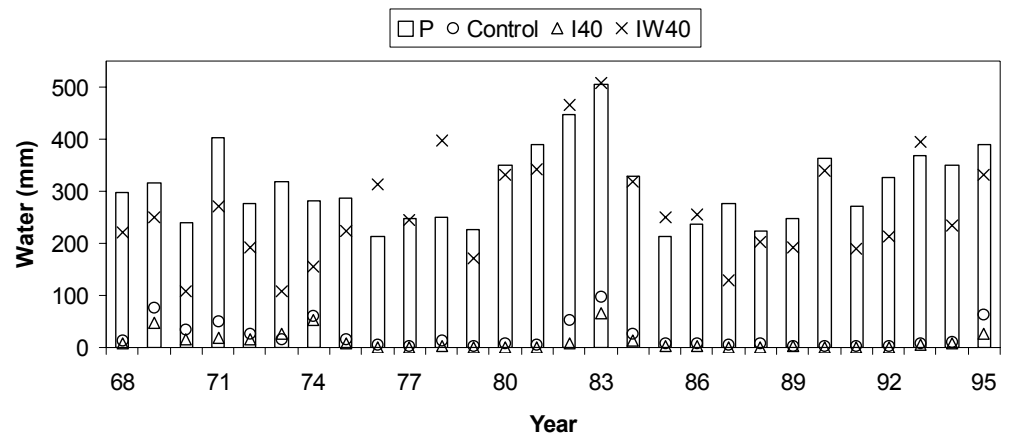

Figure 3: A comparison of annual precipitation and SHAW-estimated drainage for control, I40 and IW40 irrigation systems for Osoyoos. Note $\mathrm{P}=$ precipitation.

As discussed previously, over $80 \%$ of the variability in SHAW-estimated drainage for $\mathrm{AD}$ can be explained by the corresponding annual precipitation (Figure 2). However, at OS the linear relationship between SHAW-estimated 


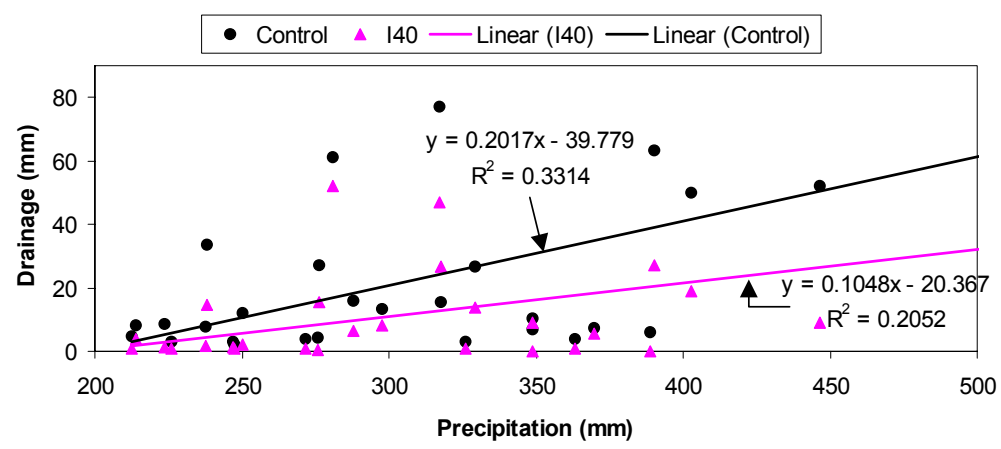

Figure 4: Relationship between annual drainage and precipitation for control and $\mathrm{I} 40$ irrigation system in Osoyoos region.

drainage and precipitation is much weaker (Figures 3 and 4). The weaker relationship at $\mathrm{OS}$ is probably related to the drier conditions for which much of the precipitation would remain in the soil profile as an increase in soil water content and not contribute to drainage. On the other hand, at AD, especially in the winter season, wetter soil conditions would result in a greater chance of drainage occurring during any precipitation (especially rainfall) event.

\section{Conclusions}

The SHAW model was run for about 30 years using daily climate data and local crop and soil conditions from two vastly different climatic regions in British Columbia, Canada. The model was run for bare soil $\backslash n o$ irrigation, and efficient and less-efficient irrigation systems to compare water losses due to drainage under each scenario. Under the efficient irrigation system SHAW estimates less drainage loss than under bare soil for the drier region. For the wetter region, drainage loss was increased slightly under efficient irrigation and a raspberry crop over bare soil. On the other hand, the SHAW-estimated amount of drainage in both regions increased substantially using the less-efficient irrigation systems. In both regions the drainage that occurs during the non-growing season cannot be controlled; however, the modelling results from this study imply that drainage losses can be minimized during the growing season using SHAW or other water and energy balance models or by installing a water content or potential sensor in the plant root zone to determine when to irrigate the crops. Note that the issue of increasing salinity in the root zone due to minimizing irrigation has not been addressed in this research. Future research will examine the potential for buildup of salts in the soil profile under the efficient irrigation system using the solute transport module of SHAW.

\section{Acknowledgements}

Funding for this research was contributed by the Canadian Network of Centres of Excellence program through the Canadian Water Network. The authors wish 
to thank Ravindra Ramnarine for excellent assistance in checking and filling gaps in the climate data and David Fallow for translating raw climate data.

\section{References}

[1] Irrigated area in British Columbia, Irrigation Factsheet \#550.100-1, BC Ministry of Agriculture and Food, 2000.

[2] Letey, J., Cardon, G.E. \& Kan, I. Irrigation efficiency and uniformity (Chapter 4). Irrigation of Agricultural Crops, ed. R.J. Lascano and R.E. Sojka, Agronomy Monograph No. 30, $2^{\text {nd }}$ Edition, ASA-CSSA-SSSA: Madison, WI, pp. 119-132, 2007.

[3] Groundwater Issues in British Columbia. BC Ministry of Environment, Victoria，BC. http://www.env.gov.bc.ca/wsd/plan protect_sustain/ground water/library/issues bc.html

[4] Flerchinger, G.N., and K.E. Saxton. Simultaneous heat and water model of a freezing snow-residue-soil system I. Theory and development. Trans. of ASAE 32(2):565-571, 1989.

[5] Hayhoe, H.N. Field testing of simulated soil freezing and thawing by the SHAW model. Can. Agric. Eng. 36:279-285, 1994.

[6] Parkin,G.W., C. Wagner-Riddle, D.J. Fallow, and D.M. Brown. Estimated Annual Water Surplus for Four Regions in Ontario. Canadian Water Resources Journal, 24: 277-292, 1999.

[7] Xiao, W., Flerchinger, G.N., Yu, Q., \& Zheng, Y.F. Evaluation of the SHAW model in simulating the components of net all-wave radiation. Transactions of the ASABE Vol. 49(5): 1351-1360, 2006.

[8] Fallow, D.J., D.M. Brown, J.D. Lauzon, and G. Parkin. 2007. Variation in risk of environmental contamination of manure/nutrient application during winter conditions across Ontario. Journal of Environmental Quality 36: 3143.

[9] Selirio, I.S., D.M. Brown, and K.M. King. Estimation of net and solar radiation. Can. J. Plant Sci., 51: 35-39, 1971. 